\title{
Prophylactic treatment with bicillin-5 and timalin of convalescence of erysipelas
}

\author{
Liviu larovoi ${ }^{1 *}$, Constantin Andriuțăª̆, Raisa Popovici², Stela Cojocaru', Lilia Cojuhari ${ }^{3}$ \\ From The 9th Edition of the Scientific Days of the National Institute for Infectious Diseases Prof Dr Matei Bals \\ Bucharest, Romania. 23-25 October 2013
}

\section{Background}

Administration of bicillin-5 alone in contemporary conditions of increasing antibiotic resistance and immunodeficiency of population is insufficient to prevent the recurrences of erysipelas. That is why a decision was made to study timalin as an immunomodulatory drug that would prevent along with bicillin- 5 the recurrence of erysipelas.

\section{Methods}

52 patients with a recent history of erysipelas and with a high risk of relapse were divided into 2 groups of 26 patients each: one the experimental group in which patients received both bicillin-5 (IM, monthly for 6 or 12 months) and timalin (10 mg IM in a day, in 10 doses) and one control group, in which only bicillin-5 was prescribed. Patients from both groups were supervised epidemiologically, clinically and immunologically for 1-4 years.

\section{Results}

The relapse rate in the experimental group was 2 times lower (19.2\%) than in the control group (38.5\%). Recurrences of erysipelas in the experimental group occurred during bicillin- 5 prophylactic treatment in 2 cases: in the third and sixth month. Out of the 10 patients with relapses in the control group, in 3 the relapses occurred before completing prophylactic treatment with bicillin- 5 .

\section{Conclusion}

Due to its immunocorrector effects, Timalin lowers the risk of relapses in erysipelas.

\footnotetext{
* Correspondence: liviu_iarovoi@yahoo.fr

'Department of Infectious Diseases, Tropical and Medical Parazitology, Nicolae Testemițanu State Medical and Pharmaceutical University, Chişinău, Republic of Moldova

Full list of author information is available at the end of the article
}

\section{Authors' details}

'Department of Infectious Diseases, Tropical and Medical Parazitology, Nicolae Testemițanu State Medical and Pharmaceutical University, Chişinău, Republic of Moldova. ${ }^{2}$ Toma Ciorbă Clinical Hospital for Infectious Diseases, Chişinău, Republic of Moldova. ${ }^{3}$ Department of Infectious Diseases, Faculty for Continuing Medical Education, Nicolae Testemițanu State Medical and Pharmacy University, Chişinău, Republic of Moldova.

Published: 16 December 2013

doi:10.1186/1471-2334-13-S1-P49

Cite this article as: larovoi et al: Prophylactic treatment with bicillin-5 and timalin of convalescence of erysipelas. BMC Infectious Diseases 2013 13(Suppl 1):P49.
Submit your next manuscript to BioMed Central and take full advantage of:

- Convenient online submission

- Thorough peer review

- No space constraints or color figure charges

- Immediate publication on acceptance

- Inclusion in PubMed, CAS, Scopus and Google Scholar

- Research which is freely available for redistribution

Submit your manuscript at www.biomedcentral.com/submit
C Biomed Central

\section{Biomed Central}

